7. Child Lang. 44 (2017), I394-I4I2. (C) Cambridge University Press 2016 This is an Open Access article, distributed under the terms of the Creative Commons Attribution licence (http://creativecommons.org/licenses/by/4.o/), which permits unrestricted re-use, distribution, and reproduction in any medium, provided the original work is properly cited.

doi:10.1017/So30500091600057X

\title{
The effect of shyness on children's formation and retention of novel word-object mappings*
}

\author{
MATT HILTON AND GERT WESTERMANN \\ Lancaster University
}

(Received I6 February 2016-Revised 26 Fuly 2016-Accepted I9 October 2016First published online 5 December 20I6)

ABSTRACT

This study set out to examine whether shyness, an aversion to novelty and unfamiliar social situations, can affect the processes that underlie early word learning. Twenty-four-month-old children $(n=32)$ were presented with sets of one novel and two familiar objects, and it was found that shyer children were less likely to select a novel object as the referent of a novel label. Furthermore, not-shy children then showed evidence of retaining these novel mappings, but shy children did not. These findings suggest that shy children's aversion to novelty and to the unfamiliar context can impact on their word learning.

\section{INTRODUCTION}

In learning language, young children face a challenging task. Not only must they work out what the words they hear mean, but they must also remember these words and their referents. Given the complexity of the speech that children hear and the limitless potential meanings of these words, this task seems almost impossible (Quine, r 960), and there has been much interest in the general mechanisms by which children are able to learn words. For example, children constrain the potential meaning of words they hear according to the shape (Landau, Smith \& Jones, 1988) and taxonomic category (Markman \& Hutchinson, 1984) of potential referents. Constraining the potential meaning of heard words in these ways is the first step towards successful word learning (McMurray, Horst \& Samuelson, 20 I 2).

[*] Matt Hilton is now in the Department of Psychology at the University of Potsdam, Germany. This research was supported in part by the ESRC (LuCiD; ES/Loo8955/r). Address for correspondence: Matt Hilton, Universität Potsdam, Karl-LiebknechtStrasse 24-25, OT Golm, I4476 Potsdam, Germany. e-mail: matt.hilton@uni-potsdam.de 
While a focus on the general mechanisms underlying word learning has helped to better understand the processes by which children acquire language, the vast variability in early language development must also be more thoroughly examined. At the age of two, the number of different words that a child can typically produce as reported by parents can range from 7 to 668 (Dale \& Fenson, I996), and a similarly wide range is demonstrated in two-year-old children's spontaneous speech production (Huttenlocher, Haight, Bryk, Seltzer \& Lyons, I99 I). Nevertheless, the large majority of children with low productive vocabularies will go on to develop language normally (Desmarais, Sylvestre, Meyer, Bairati \& Rouleau, 2008; Kelly, I 998; Whitehurst \& Fischel, I 994).

Variability in vocabulary scores has been traditionally explored by examining the extrinsic factors that can serve to affect a child's language exposure, with a particular focus on the effect of socioeconomic status. Children from poorer backgrounds are consistently shown to have lower vocabularies than their better-off peers (Evans, 2004). While at first this effect was understood to be due to differences in the amount of language to which a child is exposed (Hart \& Risely, I995), more recent research has emphasized that the quality of early language exposure is also critical (Hirsh-Pasek et al., 2015). While this research has been influential in highlighting that the quality of language exposure impacts on language acquisition, there have also been calls for a more thorough examination of the intrinsic factors that affect cognitive development (Mareschal, Johnson, Sirois, Spratling, Thomas \& Westermann, 2007). Children's behavioral styles vary widely, yet the effect of these variations is often neglected in explaining language development. One intrinsic factor that has, however, been shown to affect early language acquisition is temperament (Slomkowski, Nelson, Dunn \& Plomin, I 992), specifically shyness (Coplan \& Evans, 2009).

There have been many attempts to operationalize the construct of shyness in young children, from general constructs such as behavioral inhibition as studied in young infants (Kagan, Reznick \& Snidman, I987), to more specific conceptualizations focusing on the specific shy-type behaviors exhibited in certain contexts (e.g. peer-to-peer interactions; Gazelle, 2008). The current work draws on a broader definition of shyness, based on Putnam, Gartstein, and Rothbart's (2006) operationalization of shyness as an enduring, biologically based individual difference characterized by discomfort in (predominantly novel) social situations, as measured via the Early Childhood Behavior Questionnaire (ECBQ). Reports on use of the ECBQ have shown that shyness can be reliably measured in children from the age of i 8 months (Putnam et al., 2006).

The effect of shyness on verbal communication has been well documented; for example, it is known that shyness reduces children's verbal interaction in novel and familiar contexts (e.g. Asendorpf \& Meier, I993). While this and 
similar research has established a clear link between shyness and language development, the effect of shyness on language has typically been measured relatively late in development, when children are at least four years old (Asendorpf \& Meier, I 993; Broberg, Lamb, Hwang \& Bookstein, I990; Coplan \& Weeks, 2009; Crozier \& Badawood, 2009; Crozier \& Perkins, 2002; Evans, I 996; Reynolds \& Evans, 2009). Recently, however, interest has turned to the effect of shyness on the critical early stage of language acquisition during the second year of life (Smith Watts et al., 20I4). Smith Watts and colleagues examined how shyness impacts on receptive and productive language development, and reported that shyness is more strongly related to expressive than receptive vocabulary size. These authors argued that shy children's lower language ability during the second year of life can be explained in terms of a reticence to respond, rather than any difficulty in learning the meaning of words. Shy children's reticence to respond has been demonstrated in home settings (Reynolds \& Evans, 2009) and in experimental settings (Crozier \& Perkins, 2002), and it is also supported by research in non-Western cultures (Crozier \& Badawood, 2009).

One critical limitation of the extant literature in support of a reticence to respond explanation is that it does not predict an effect of shyness on receptive vocabulary. However, there are many reports of a relation between shyness and receptive vocabulary (Crozier \& Badawood, 2009; Crozier \& Hostettler, 2003; Crozier \& Perkins, 2002; Rudasill, Prokasky, Tu, Frohn, Sirota \& Molfese, 2014; Slomkowski et al., I992; Spere, Schmidt, Theall-Honey \& Martin-Chang, 2004). Interestingly, even Smith Watts and colleagues (2014) found relations between receptive vocabulary and shyness, but they argued that their data supported a reticence to respond explanation because the relations between shyness and productive vocabulary were more pronounced. Here we suggest that further insights into the ways in which shyness affects language development can be achieved by investigating the role of shyness in the processes that support word learning.

Laboratory examinations of children's "remarkable" ability to acquire words during the second year of life often employ fast mapping tasks that demonstrate the ability to rapidly associate novel labels with novel objects (Axelsson, Churchley \& Horst, 201 2; Halberda, 2006; Horst \& Samuelson, 2008; Horst, Samuelson, Kucker \& McMurray, 20 I ; Spiegel \& Halberda, 20II; Vlach \& Sandhofer, 20I2). In these tasks, children are usually presented with a novel object alongside objects for which a label is already known and are asked to identify the object referred to by a novel pseudoword (e.g. "Where's the blicket?"; Markman \& Wachtel, I988). Children begin to demonstrate the ability to pick the novel object from the age of I 5 months (Markman, Wasow \& Hansen, 2003), and more recent work

$$
\text { I } 396
$$


indicates that some children may do this as early as $\mathrm{I} 2$ months $(\mathrm{Xu}$, Cote $\&$ Baker, 2005).

Nevertheless, a closer look at the literature reveals considerable individual differences in fast mapping ability. For example, in a study investigating the age-related development of fast mapping, Wilkinson, Ross, and Diamond (2003) classed $25 \%$ of the under 42 -month-old children in their experiment as unreliable fast mappers. In other studies 24-month-old children selected the novel object only on approximately three-quarters of trials (Horst \& Samuelson, 2008; Twomey, Ranson \& Horst, 2014). Similarly, in a study by Mervis and Bertrand (1994) with I6-20-monthold children, half of the children did not reliably select the novel object upon hearing a novel label.

Critically, children's selection of the novel object as the referent of a novel label has been attributed to a novelty bias, which is so strong at i 8 months that it leads children to select the novel object as the referent of even a familiar word (Samuelson, Kucker \& Spencer, 20I6). Even at 24 months of age, children reliably select a familiar target object (Horst \& Samuelson, 2008), but they also select a novel object as the referent of a novel label when competitors are nameless but pre-familiarized objects (Horst et al., 20II), demonstrating the importance of novelty preference in driving children's object selection on referent selection trials. Individual differences in performance on referent selection trials may therefore be explained in terms of differences in novelty preference. That novelty preference is critical in supporting referent selection would indicate that shyness could come to bear on this ability, because we know that shy children are averse to novelty (Kagan et al., I987). This aversion to novelty could mean that shy children's novelty preference is reduced in comparison to not-shy children.

Even once the novel object is selected as the referent of a novel word, this novel word-object mapping is not necessarily learned. A number of studies have argued that children's ability to select the correct referent and the ability to retain the label-object mapping over a period of time are governed by related, but separate, processes (Axelsson et al., 2012; Horst \& Samuelson, 2008; Kucker, McMurray \& Samuelson, 20 I5; Munro, Baker, McGregor, Docking \& Arciuli, 20I2). In tests of retention, children are presented with (usually three) objects for which they have fast mapped novel labels and are asked for one of these objects using its novel label. Despite success in forming the initial word-object mappings, children often have difficulty retaining these mappings. For example, in one typical study Horst and Samuelson (2008) found that after a 5-minute delay, 24-month-old children were unable to select the correct object above levels that would be expected by chance. 
We know that extrinsic factors can affect whether a mapping is retained. Horst and Samuelson (2008) found that by reinforcing the mapping by ostensively naming the object (e.g. by pointing and labeling) after the child had made the initial word-object mapping, the likelihood that it would be retained was increased. This finding suggested that attention to the referent during referent selection determines whether the novel wordobject mapping will be retained, supported by subsequent work which found that highlighting the target object by illuminating it and dampening attention to competitors by partially covering them also increased retention (Axelsson et al., 2012). This work suggested that the attention directed toward the target during referent selection alone is not sufficient to support retention. Again, then, shy children's aversion to novelty could modulate their attentional pattern across the objects during referent selection, which would impact on their retention of any word-object mappings.

Children are clearly variable in their demonstration of the mechanisms that support word learning, and we suggest that shyness could explain some of this variability. If shyness impacts on the most basic and early processes of word learning, this could help to explain the relation between shyness and language development as measured more generally (e.g. Spere et al., 2004). Specifically, one can assume that children who are better able to focus their attention on the novel object during labeling should be better able to retain the word-object mapping. We hypothesize that shyness can affect retention of novel word-object mappings formed via referent selection by modulating children's attention during referent selection. Such a hypothesis is in line with recent accounts arguing that differences in engagement with objects can explain differences in word learning and categorization of these objects (e.g. Perry, 20I5). If shy children demonstrate lower levels of retention than their not-shy peers, it would mean that shyness is affecting the acquisition of language from one of its earliest stages: the initial mapping of a label to its referent. Such a fine-grained analysis of the effects of shyness on the formation of labelobject mappings, rather than focusing solely on vocabulary size or language production, means that we can begin to understand the precise ways in which language is shaped by shyness.

In the present study, two-year-old children took part in both referent selection and retention tests of mapping novel labels to novel objects. A sample of children who varied in their shyness completed the same referent selection trials in which they were presented with one novel object alongside two familiar objects and were asked for a novel label. Trials were included in which children were asked for a familiar object. After a 5-minute break, all children then took part in retention trials. We also investigated whether external directing of attention to the target object via 
ostensive naming of targets during referent selection facilitated shy children's retention.

\section{METHOD}

\section{Participants}

Thirty-two typically developing 24-month-old children participated $(M=$ $24 \mathrm{~m}, 8$ days, $\mathrm{SD}=$ I I days; range $=23 \mathrm{~m}$, I 9 days to $24 \mathrm{~m}, 29$ days; $\mathrm{I} 6$ girls and $\mathrm{I} 6$ boys). All children were monolingual, predominantly from middle-class families of Caucasian ethnicity living in the north-west of England, UK. Families were recruited by contacting parents who had previously indicated interest in participating in child development research. Parents' travel expenses were reimbursed and children were offered a storybook for participating. Data from nine additional children were excluded from analyses due to experimenter error $(n=\mathrm{I})$, parental involvement $(n=2)$, refusal to complete the task $(n=3)$, and the parent not returning the questionnaire $(n=3)$.

The Early Childhood Behavior Questionnaire (ECBQ) was used to assess children's shyness as an enduring, biologically based individual difference. The ECBQ asks parents to rate on a scale from 1 to 7 how often their child has demonstrated particular behaviors over the previous two weeks ( $\mathrm{I}=$ 'never', $7=$ 'all the time'), as a means of assessing the child's score on eighteen fine-grained subdimensions of temperament. While these subdimensions include areas such as attention focusing, activity level, and high- or low-intensity pleasure, the shyness subdimension was of particular interest for the current study. The shyness scale consists of twelve items that assess how children react in situations that elicit shy behavior, for example "When approaching unfamiliar children playing, how often did your child watch rather than join?" and "In situations where s/he is meeting new people, how often did your child become quiet?". Each child was scored from I to 7 by averaging their parents' responses to the twelve questions relating to shyness (after correcting for reverse coded questions). A score of $\mathrm{I}$ is considered the least shy, and a score of 7 is considered the most shy. Standardized Cronbach's alpha for the shyness measure was 0.76 . Once all data were collected, the median score for all children was calculated $(3.67)$. Children scoring above the median formed the shy group and those scoring less than the median formed the not-shy group. Three children's scores equaled the median, and they were randomly assigned to a group, ensuring equal sample size $(n=\mathrm{I} 6)$. There were equal numbers of boys and girls $(n=8)$ in each group. There was no difference between groups in age $\left(t(30)={ }_{1} \cdot 45, p\right.$ $=\cdot \mathrm{I} 6)$. Unsurprisingly, children in the not-shy group were scored as less shy $(M=2 \cdot 73, S D=0.62)$ than children in the shy group $(M=4 \cdot 14, S D=$ 
$0.48)(t(30)=-7 \cdot 19, p<.00 \mathrm{I})$. Shyness scores were calculated after the testing session had taken place, which meant that the shyness grouping of the participants was not evident during testing.

In order to examine whether ostensive naming interacts with shyness to affect referent selection and retention, eight boys and eight girls were assigned to an ostensive naming and a no ostensive naming condition. Assignment of children to ostensive and no ostensive naming conditions occurred before it was possible to calculate a median shyness score, so children were randomly assigned to each condition prior to each testing session. There was no difference between conditions in age $(t(30)=-\mathbf{I} \cdot 34$, $p=\cdot 19)$. As expected by a random assignment, there were equal numbers of not-shy children in the ostensive naming $(n=8 ; 5$ girls), and no ostensive naming $(n=8 ; 3$ girls) conditions. Similarly, there were equal numbers of shy children in the ostensive naming $(n=8 ; 3$ girls $)$ and no ostensive naming $(n=8 ; 5$ girls) conditions.

\section{Stimuli}

The same stimuli were used in both conditions. Eleven objects, selected because they are easily named by 24-month-olds, acted as familiar objects, and consisted of animals (duck, elephant, fish, pig), vehicles (car, motorbike, helicopter), and household objects (spoon, fork, cup, and ball). Four novel objects, selected because they are not normally familiar to 24month-old children, were a plastic roller, a wooden massager, a tea strainer, and a miniature dumbbell (see Figure I). Four distinct nonwords (cheem, koba, sprock, tannin) were used to name the novel objects, taken from previous research using similar methodology (Behrend, Scofield \& Kleinknecht, 200I; Horst \& Samuelson, 2008; Markson \& Bloom, I997; Samuelson \& Horst, 2007). The assignment of each name to each novel object was randomized across participants. To ensure the objects would be familiar and novel to each participant as expected, parents were shown photographs of the objects before the experiment began and confirmed their familiarity or novelty. All objects were similar in size (approximate mean size $5 \mathrm{~cm} \times 6 \mathrm{~cm} \times 9 \mathrm{~cm}$ ). The objects were presented on a wooden tray, divided into three equal compartments for the objects to be placed.

PROCEDURE AND DESIGN

Prior to their visit to the lab, parents completed the ECBQ, and during their visit children took part in the word learning task.

\section{Word learning task}

Warm-up trials. During the task children sat on their parent's lap across a white table from the experimenter. Once settled, the warm-up trials began. 

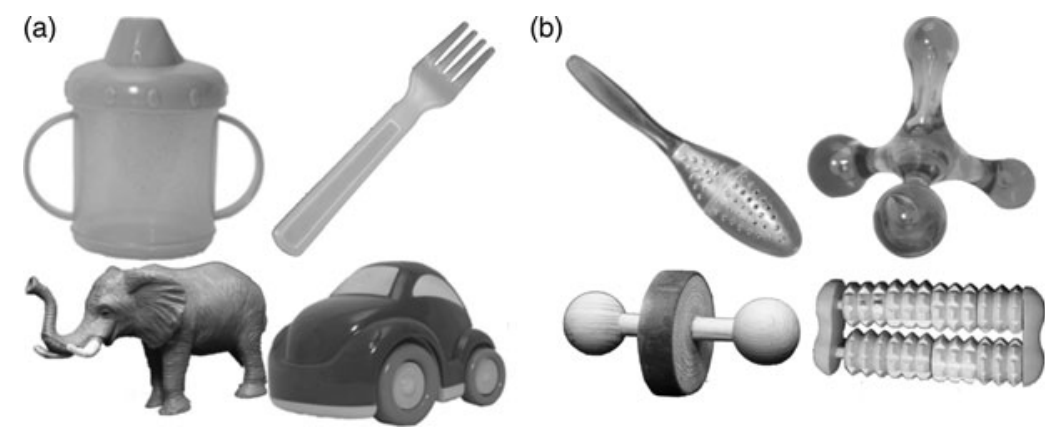

Fig. I. A subset of the stimuli used in the experiment. Panel (a) shows examples of the familiar objects used in the experiment. Panel (b) shows the four unfamiliar objects that were used in the experiment.

All trials consisted of three objects being presented to the child on the tray. For warm-up trials, the three objects were familiar and their purpose was to introduce the child to the forced-choice task, and to ensure that they understood the instructions of the experimenter. For each trial the experimenter presented the objects and asked for the target six times (i.e. "Wow a duck! Where's the duck? See the duck! Find the duck! Get the duck! Can you get the duck?"). The experimenter then slid the tray forward into reaching distance for the child, and gave the child the opportunity to retrieve the requested object. If correct, the child was praised, and if incorrect, the child was corrected. The order in which the objects were requested was randomly determined prior to testing. The three familiar objects presented on warm-up trials were not presented in subsequent referent selection trials. Warm-up trials continued until children had correctly selected each referent once. The majority of children needed no more than three warm-up trials ( 8 children needed four warm-up trials and one child needed six warm-up trials.)

Referent selection trials. The referent selection trials began immediately after the warm-up trials. Referent selection trials proceeded in the same manner as the warm-up trials, but differed in three ways. First, two of the objects were familiar and one was novel. Second, neither praise nor corrections were given following the child's referent selection. Third, children were offered the chance to explore the three objects for 30 seconds before they were asked to select an object. During this exploration time, the three objects were presented on the tray to the child, and the child and caregiver played with the objects for 30 seconds. During this exploration, parents were instructed to avoid labeling or asking for labels for the objects, and if needed the experimenter directed the child's attention to each of the objects at least once, either by pointing at it, or if 
that was unsuccessful, by maneuvering it into the child's line of vision. Once 30 seconds had elapsed, the objects were returned to their positions on the tray, and the child was asked for the target object.

Once children had selected an object, it was returned to its position on the tray. Children in the ostensive naming condition then saw the target object ostensively named (irrespective of whether they had correctly chosen the target object or not), meaning that the experimenter pointed at the target object and labeled it (e.g. "It's a car."). Children in the no ostensive naming condition saw the experimenter point to the target object and say "There it is". To ensure that children in each condition heard the label an equal number of times (which was relevant for the subsequent retention test), children in the ostensive naming condition heard the label one time fewer during the initial request, by removing a labeling phrase (e.g. "Where's the koba?"). This arrangement meant that children in both conditions heard the object labeled six times. The object label was spoken multiple times, in line with previous research (e.g. Axelsson et al., 2012).

Each child was presented with four sets of three objects, and each set was shown twice. In one of these presentations the child was asked for a novel object, and in the other was asked for a familiar object. The objects comprising each set and the labels assigned to each novel object were randomized across children. The order of sets and trials was pseudorandomized, ensuring that any trial type (i.e. familiar or novel) was not presented on more than two consecutive trials.

Retention trials. Following the referent selection trials there was a 5-minute break, during which the child was offered crayons and paper for coloring. This break was to ensure that any retention in the following trials was the product of long-term memory (following Horst \& Samuelson, 2008). After the 5-minute break, the child participated in four retention trials, which did not differ between conditions. Again, children were presented with sets of three objects. These were all novel objects that had been presented and labeled during referent selection. Across the four retention trials, each novel object was the target once. The two novel objects presented alongside the target were randomly determined. On presentation of each set, the child was asked to select the target once (e.g. "Where's the koba?"). The tray was slid forward and the child indicated the chosen object. The order of trials was randomized across participants.

\section{RESULTS}

\section{Word learning tasks}

Each child took part in four familiar and four novel referent selection trials. For each, a 'proportion of correct choices' measure was calculated by dividing the number of correct responses by the total possible (i.e. 4 for 
familiar and 4 for novel referent selection trials). One participant (shyness score $=2.5$ ) did not respond on two referent selection trials, and one participant (shyness score $=\mathbf{2 \cdot 7}$ ) did not respond on one referent selection trial. A response was elicited from children on all other referent selection trials. A response was elicited for all retention trials.

Performance on referent selection trials replicated previous work (e.g. Horst \& Samuelson, 2008). Overall, selection of the correct familiar object was higher than would be expected by chance $(M=0.87, S D=0.18)$ $(t(3 \mathrm{I})=\mathrm{I} 6.94, p<.00 \mathrm{I} ; d=2.99)$. Furthermore, in trials where a novel label was heard, children selected the novel object significantly above chance, demonstrating the ability to fast map $(M=0.59, S D=0.32)$ $(t(3 \mathrm{I})=4.60, p<.00 \mathrm{I} ; d=0.8 \mathrm{I})$. Overall, children were better at selecting the familiar than the novel object $(t(3 \mathrm{I})=6 \cdot \mathrm{I} 2, p<\cdot 00 \mathrm{I} ; d=\mathrm{I} \cdot 08)$. As expected, because the critical manipulation happened after children had selected the referent, there was no difference between ostensive naming conditions on either familiar referent selection trials $(t(30)=0.73, p=.47)$, or novel referent selection trials $\left(t(30)={ }_{\mathrm{I}} \cdot 28, p=\cdot 2 \mathrm{I}\right)$.

The following analyses only included retention trials in which the child had correctly selected the target during the corresponding novel referent selection trials. For example, if the child had chosen the car when asked for the cheem during referent selection, the retention trial for the mapping of cheem was not included (following Horst \& Samuelson, 2008). Overall, children were unable to retain the object-label mappings they had made during referent selection, selecting the target object no more often than would be expected by chance $(M=0.38, S D=0.35)(t(3 \mathrm{I})=0.82, p=.42)$. We investigated whether particular objects were more likely to be selected than others during referent selection and retention trials. We found that children did not select certain familiar objects more often than others $\left(\chi^{2}\right.$ (7, $N=$ I 28) = г.०8, $p>\cdot 99)$. Likewise, novel object selection was not greater for any particular object $\left(\chi^{2}\left(3, N=\mathrm{I}_{25}\right)=2 \cdot 56, p=\cdot_{4} 6\right)$. Again during the retention task children did not choose any novel objects more often than others $\left(\chi^{2}(3, N=\mathrm{I} 28)=5 \cdot 19, p=\cdot 16\right)$.

Shyness and referent selection. Shyness was not significantly related to children's referent selection on familiar label trials $\left(r_{\mathrm{s}}(30)=-0 \cdot 27, p=._{4}\right)$, but shyness was significantly related to children's referent selection on novel label trials $\left(r_{\mathrm{s}}(30)=-0.38, p=.03\right)$, demonstrating that an increase in shyness score meant a decrease in proportion of trials on which the novel object was selected as the referent of a novel label.

The observed effects were specific to scores on the shyness subscale of the ECBQ. There was no relation between novel referent selection and negative affectivity, the core factor of temperament of which shyness is a subscale $\left(r_{\mathrm{s}}(30)=-0 \cdot \mathrm{I}_{4}, p=\cdot 44\right)$, or with the other core factors: surgency $\left(r_{\mathrm{s}}(30)=-0.12, p=\cdot 50\right)$ and effortful control $\left(r_{\mathrm{s}}(30)=0.07, p=\cdot 70\right)$. There 
was also no relation between novel referent selection other subscales of Negative Affectivity, such as fear $\left(r_{\mathrm{s}}(30)=-0 \cdot I_{4}, p=\cdot 45\right)$, cuddliness $\left(r_{\mathrm{s}}(30)=-0.03, p=.89\right)$, or sociability $\left(r_{\mathrm{s}}(30)=-0.06, p=.76\right)$.

We also wanted to examine the extent to which shyness impacted on referent selection by examining performance in relation to chance. Shyness groups were thus compared.

As shown in Figure 2, children in the not-shy group were better than would be expected by chance at selecting the familiar object $\left(t\left(\mathrm{I}_{5}\right)=\mathrm{I} 6 \cdot 84\right.$, $p<.00 \mathrm{I} ; d=4.2 \mathrm{I})$ and novel object $\left(t\left(\mathrm{I}_{5}\right)=5.76, p<.00 \mathrm{I} ; d=\mathrm{I} \cdot 44\right)$. In contrast, children in the shy group were better than would be expected by chance only at selecting the familiar object ( $\left.t\left(\mathrm{I}_{5}\right)=9 \cdot 96, p<\cdot 00 \mathrm{I} ; d=2 \cdot 49\right)$, but not at selecting the novel object $\left(t\left(\mathrm{I}_{5}\right) \mathrm{I}_{\mathrm{I}_{5}} \mathrm{~F}_{3}, p=\cdot_{\mathrm{I}}\right)$.

In order to further examine how shyness affects children's referent selection, a 2 (trial type: familiar or novel) $\times 2$ (shy group) mixed Analysis of Variance (ANOVA) was performed. This analysis revealed a main effect of trial type $\left(F(\mathrm{I}, 30)=40.00, p<.00 \mathrm{I}, \eta_{\mathrm{p}}^{2}=.55\right)$, meaning that children chose the target often more often on familiar trials $(M=0.87, S D=0.18)$ than novel trials $(M=0.59, S D=0.32)$. There was no interaction between trial type and shyness $(F(\mathrm{I}, 30)=3.09, p=.09)$. As expected, there was a significant main effect of shyness group $(F(\mathrm{I}, 30)=\mathrm{IO} \cdot \mathrm{I} 6, \quad p=.003$, $\left.\eta_{\mathrm{p}}^{2}=.25\right)$, meaning that children in the not-shy group chose the target object more often $(M=0.84, S D=0.24)$ than children in the shy group $(M=0.62, S D=0.30)$.

Shyness and retention trials. There was no relation between shyness and retention $\left(r_{\mathrm{s}}(30)=-0.29, p=\cdot \mathrm{II}\right)$ when trials testing retention of novel mappings not formed during referent selection were excluded. However, as shown in Figure 3, children in the not-shy group were significantly better at retaining the word-object mappings than would be expected by chance $\left(t\left(\mathrm{I}_{5}\right)=2.46, p=.03 ; d=0.6 \mathrm{I}\right)$. In contrast, children in the shy group performed at chance during retention $\left(t\left(\mathrm{I}_{5}\right)=-0.67, p=.52\right)$. A 2 (shy group) $\times 2$ (ostensive naming) Analysis of Variance (ANOVA) revealed no main effect of ostensive naming $(F(\mathrm{I}, 28)=0.07, p=.79)$, no main effect of shyness $(F(\mathrm{I}, 28)=3.65, p=.07)$, and no significant interaction $(F(\mathrm{I}, 28)=0.76, p=\cdot 39)$, demonstrating that ostensive naming had no effect on retention.

It was possible that shy children learned the novel word-object mappings even though they did not select the novel object during referent selection. Therefore, we also examined whether shyness affected children's retention when averaged across all retention trials, regardless of whether the novel object was selected as the referent of the novel word during referent selection. No relation was found $\left(r_{\mathrm{s}}(30)=-0 \cdot 18, p=\cdot 32\right)$. Shy children did not retain the word-object mappings above levels expected by chance 


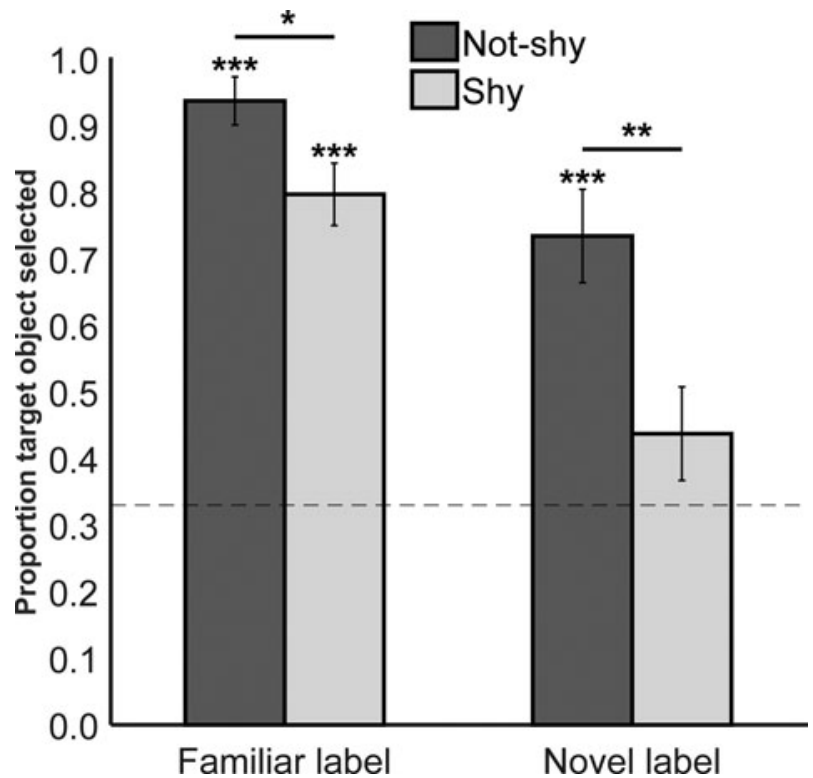

Fig. 2. Shy and not-shy children's proportion of target choices during referent selection trials. The dotted line represents chance $(0.33)$. Error bars represent I SE. * $p<.0_{5}$, ** $p$ $<. \mathrm{II}, * * * *<$.००I (Bonferonni corrections apply to between-groups comparisons).

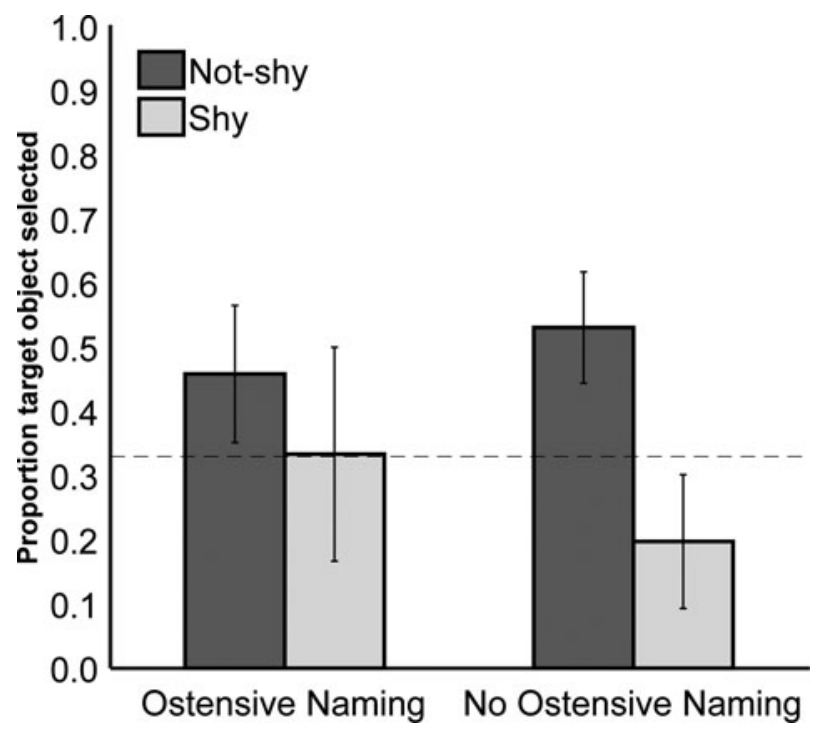

Fig. 3. Proportion of word-object mappings retained by not-shy and shy children after a 5-minute break, split by ostensive naming condition. The dotted line represents chance (.33). Error bars are I SE. 
$(M=0.38, S D=0.29)\left(t\left(\right.\right.$ I $\left.\left._{5}\right)=0.62, p=.54\right)$, whereas not-shy children did retain the mappings $\left(M=0.45, S D=0 . \mathrm{I}_{6}\right)(t(\mathrm{I} 5)=3.0 \mathrm{I}, p<.0 \mathrm{I} ; d=0.75)$.

\section{DISCUSSION}

The present study found that shy children were less likely than not-shy children to correctly identify a requested familiar or a novel object from a set of three. Specifically, shy children performed at chance in trials in which a novel object was requested using a novel label, whereas not-shy children performed above chance. Furthermore, after a 5-minute break, shy children did not show evidence of retaining the mappings that they had previously made, whereas not-shy children demonstrated retention above levels expected by chance. This study found no evidence that ostensive naming affected children's retention of novel word-object mappings. Importantly, our results emphasize that a child's emerging temperament can affect basic processes involved in word learning. When considered alongside the finding that shy children do not reliably retain any mappings that they have made, this study suggests that intrinsic factors, and not just differences in input, are important contributors to variability in early language acquisition.

The results of our study suggest that the mapping of a novel label to a novel object is not as robust and automatic for all children as has been previously reported (Halberda, 2003; Horst \& Samuelson, 2008), and it shows that shy children as a group do not demonstrate use of fast mapping to disambiguate the referents of words that they hear in a lab setting. Furthermore, the mappings that were formed by shy children were not then subsequently retained. The present study also indicated that selection of a correct familiar referent is similarly affected by shyness, as expected in light of recent suggestions that familiar word recognition is supported by the same processes as the mapping of a novel word to a novel object (McMurray et al., 2012).

Several hypotheses have been proposed to explain shy children's lower vocabulary scores, and each hypothesis offers a different explanation for the findings of the present study. The "I know it but won't say it" hypothesis (Coplan \& Evans, 2009) suggests that shy children learn words normally, but are reticent to demonstrate this ability. This hypothesis thus assumes that shyness does not affect receptive vocabulary, supported by a recent paper which reported that expressive vocabulary size is more affected by shyness than receptive vocabulary size (Smith Watts et al., 20I4). However, the present study employed a measure of receptive language ability, which suggests that a reticence to respond is not an adequate explanation of the relation between shyness and language development, instead supporting earlier work that has reported a relation

$$
\text { I } 406
$$


between shyness and receptive language development (e.g. Spere et al., 2004).

Furthermore, while the present study found that shy children were less likely to respond correctly when asked to select a familiar object, and to map novel labels onto novel objects, shy children did not simply refuse to respond. In fact, across all participants only three trials (out of a possible 384) were coded as non-responses. The "I know it but won't say it" hypothesis does not explain why shy children will offer a supposedly incorrect response; their behavior may be better described as "I may know it, but won't say it, but I will say something anyway." Importantly, then, this study demonstrates that simply eliciting a response from a shy child may not provide a valid measure of their knowledge.

The present study found that shy children do not show evidence of retaining the (few) word-object mappings that they successfully made during referent selection. Pre-familiarization of stimuli prior to labeling usually boosts levels of retention (Kucker \& Samuelson, 2012), so it is remarkable that even under these conditions shy children showed no retention of any novel word-object mappings. This finding clearly demonstrates that shyness does not only impact on in-the-moment online processes, but also the longer-term processes that support retention necessary in the acquisition of vocabulary. Beyond demonstrating that receptive language is not immune to the effects of shyness, these findings suggest that previous research describing poor retention on the group level (Horst \& Samuelson, 2008) might be explained by not having included shyness as a covariate. Again, the failure of shy children to retain mappings cannot be explained by reticence to respond; they offered a response on all retention trials, too.

Apart from the reticence to respond explanation, several alternative explanations have been put forward to account for the differences between shy and not-shy children on measures of language development. One, known as the "lack of practice" hypothesis (Coplan \& Evans, 2009), argues that shy children tend to avoid social situations, and in doing so limit both their exposure to others' language and an opportunity to practice language while receiving contingent feedback. Empirical support for this hypothesis has been found, for example, in the discovery that shy children speak less than their not-shy peers in experimental settings (Crozier \& Perkins, 2002) and at home (Reynolds \& Evans, 2009). Again, this explanation draws heavily on language development as measured in terms of vocabulary size, and in light of the present findings, assumes that children's ability to form and retain object-label mappings can be moderated by experience and practice. To explain our results according to this hypothesis, one would have to assume that children's previous experience and interactions are shaped by shyness to such an extent that either shy children miss out on 
the opportunity to develop the understanding that requests should be responded to correctly, or that they restrict their language input to the extent that they cannot acquire the mechanisms needed to map novel labels onto novel objects. Therefore, while the lack of practice might well explain a lower vocabulary size in young children due to lack of exposure, it is unlikely that it affects the mechanisms of word learning per se, particularly given the shift towards an understanding of the domaingeneral nature of the processes that support this ability (e.g. Samuelson \& Smith, I 998).

A third hypothesis is based on findings that older shy individuals are less likely to take risks (Addison \& Schmidt, I 999; Levin \& Hart, 2003). While it is still unclear whether such an aversion to risk has emerged in shy children at this young age, we argue that it is possible that shy children are less likely to rely on a guess when responding, which also explains the effect of shyness on expressive vocabulary (Coplan \& Evans, 2009). The effect may be particularly pronounced in tests of word learning that involve novel words with ambiguous referents, as in the present study where children were required to map the novel word to the novel object using only novelty as a cue. Novelty is inherently ambiguous and does not rule out competitors as potential referents with certainty. Therefore, an aversion to risk could disrupt children's use of novelty as a cue to referent selection.

Alongside an aversion to risks, shy children also demonstrate inhibited approach and discomfort in social situations involving novelty (Putnam et al., 2006). Most experimental settings are fundamentally unfamiliar to a young participant. Tests are typically carried out by a researcher who is unknown to the child, often in an unfamiliar room (Heibeck \& Markman, I 987; Horst \& Samuelson, 2008; Horst et al., 20II; Horst, Scott \& Pollard, 20ıо; Spiegel \& Halberda, 20II; Zosh, Brinster \& Halberda, 2013). This inhibited approach may also have come to bear on performance in the present study. When shy children were certain that their response was correct, they were able to overcome the problems posed by the unfamiliar setting to some extent, because as a group they reliably selected a familiar object when requested. Yet shy children selected the correct familiar object less often than not-shy children, suggesting that an unfamiliar setting can impact on shy children's demonstration of label referents. Furthermore, when asked for a novel label, shy children were just as likely to select a familiar object as the novel object. It is therefore likely that shy children's reluctance to rely on ambiguity in responding to requests, alongside their aversion to novelty, produce a familiarity preference on novel label trials.

These effects must, however, be further teased apart in order to better understand how best to tailor the testing environment so as to not disadvantage shy children. Reducing the unfamiliarity of the testing 
procedure could reduce shy children's preference for familiar objects, and may allow children to feel more comfortable in taking a risk and making use of novelty as a cue to the correct referent on novel label trials. However, shy children's aversion to novelty may affect their responses by restricting their attention to and encoding of the novel label-object mapping, supported by the finding that even on trials where they attended to the novel object enough to select it during referent selection, these mappings were not retained, unlike the mappings formed by the not-shy children. It may be the case that the encoding of the word-object mapping by shy children is different to that of not-shy children, calling for more implicit measures of children's mapping of novel labels to novel objects in order to explore the effect of shyness on attention during the formation of the mappings.

Interestingly, ostensive naming did not facilitate shy children's retention of the novel word-object mappings, but no effect of ostensive naming was found overall either. This finding may then suggest that pointing at and labeling the object was not a robust enough cue to support retention. Instead, it may be necessary to move the object away from competitors during ostensive naming (e.g. by lifting the target off of the tray before labeling; see also Axelsson, Perry, Scott \& Horst, 20I6), and future work will take this suggestion into account.

This study has shed further light on previous explanations for the effect of shyness on measures of language development, and examined whether they can account for the effect of shyness on the processes used to form wordobject mappings. While researchers have been confident in claiming that this effect can be best explained in terms of shy children's reticence to respond (Smith Watts et al., 20I4), the current study found that shy children will respond to questions even when they are posed by an unfamiliar adult. The 'lack of practice' argument also offers an inadequate explanation for these findings, given that it is based on the unlikely assumption that lack of practice has impaired the very mechanisms by which they map words to objects. The explanation that best fits the present data is that shy children's aversion to risk-taking and novelty serves to enhance their preference for familiar objects on novel label trials, and their attention to and encoding of any possible word-object mappings is disrupted.

Most importantly, this study is a clear demonstration that intrinsic factors related to emerging temperamental domains can affect the acquisition of language by moderating the processes by which shy children disambiguate and retain word-object mappings. Therefore, variability in early language acquisition must be explored in terms of differences in the mechanisms by which language is acquired, not only differences in input. The present study has shown that, given the same input and cues to word learning, shy 
children respond differently from their not-shy peers. In further exploring the effect of emerging temperament on the processes involved in word learning, the field can be better informed in identifying children for whom language acquisition is more difficult, or just different.

\section{REFERENCES}

Addison, T. L. \& Schmidt, L. A. (I999). Are women who are shy reluctant to take risks? Behavioral and psychophysiological correlates. Fournal of Research in Personality 3, 352-7.

Asendorpf, J. B. \& Meier, G. H. (I993). Personality effects on children's speech in everyday life: sociability-mediated exposure and shyness-mediated reactivity to social situations. Fournal of Personality and Social Psychology 64(6), 1072-83.

Axelsson, E. L., Churchley, K. \& Horst, J. S. (2012). The right thing at the right time: why ostensive naming facilitates word learning. Frontiers in Psychology 3. Online: <https://doi. org/10.3389/fpsyg.201 2.00088>.

Axelsson, E. L., Perry, L. K., Scott, E. J. \& Horst, J. S. (2016). Near or far: the effect of spatial distance and vocabulary knowledge on word learning. Acta Psychologica r63, 8 I-7.

Behrend, D. A., Scofield, J. \& Kleinknecht, E. E. (200I). Beyond fast mapping: young children's extensions of novel words and novel facts. Developmental Psychology 37(5), $698-705$.

Broberg, A., Lamb, M. E., Hwang, C. P. \& Bookstein, F. L. (I990). Factors related to verbal abilities in Swedish preschoolers. British Fournal of Developmental Psychology 8(4), 335349 .

Coplan, R. J. \& Evans, M. A. (2009). Shyness and language [Special issue]. Infant and Child Development $\mathbf{1 8}(3), 2 \mathrm{I} \mathrm{I}-305$.

Coplan, R. J. \& Weeks, M. (2009). Shy and soft-spoken: shyness, pragmatic language, and socio-emotional adjustment in early childhood. Infant and Child Development $\mathbf{1 8}(3)$, $238-54$.

Crozier, W. R. \& Badawood, A. (2009). Shyness, vocabulary and children's reticence in Saudi Arabian preschools. Infant and Child Development 18, 255-70.

Crozier, W. R. \& Hostettler, K. (2003). The influence of shyness on children's test performance. British Fournal of Educational Psychology 73(3), 3 I 7-28.

Crozier, W. R. \& Perkins, P. (2002). Shyness as a factor when assessing children. Educational Psychology in Practice 18, 239-44.

Dale, P. \& Fenson, L. (I996). Lexical development norms for young children. Behavior Research Methods, Instruments $\&$ Computers 28(I), I25-7.

Desmarais, C., Sylvestre, A., Meyer, F., Bairati, I. \& Rouleau, N. (2008). Systematic review of the literature on characteristics of late-talking toddlers. International fournal of Language E Communication Disorders 43(4), $36 \mathrm{I}-89$.

Evans, G. W. (2004). The environment of childhood poverty. American Psychologist 59, 77-92.

Evans, M. A. (1996). Reticent primary grade children and their more talkative peers: verbal, nonverbal, and self-concept characteristics. Fournal of Educational Psychology 88(4), 739-49.

Gazelle, H. (2008). Behavioral profiles of anxious solitary children and heterogeneity in peer relations. Developmental Psychology 44(6), 1604-24.

Halberda, J. (2003). The development of a word-learning strategy. Cognition 87, B23-4.

Halberda, J. (2006). Is this a dax which I see before me? Use of the logical argument disjunctive syllogism supports word-learning in children and adults. Cognitive Psychology 53, 3 I $0-44$.

Hart, B. \& Risley, T. R. (1995). Meaningful differences in the everyday experience of young American children. Baltimore, MD: Paul H Brookes Publishing.

Heibeck, T. H. \& Markman, E. M. (1987). Word learning in children: an examination of fast mapping. Child Development 58, го2 I-34. 
Hirsh-Pasek, K., Adamson, L. B., Bakeman, R., Owen, M. T., Golinkoff, R. M., Pace, A., ... Suma, K. (2015). The contribution of early communication quality to low-income children's language success. Psychological Science 26(7), I07 I-83.

Horst, J. S., and Samuelson, L. K. (2008), Fast mapping but poor retention by 24-month-old infants. Infancy $\mathbf{1 3}, \mathbf{1} 28-57$.

Horst, J. S., Samuelson, L. K., Kucker, S. C. \& McMurray, B. (20 I I). What's new? Children prefer novelty in referent selection. Cognition II8(2), 234-44.

Horst, J. S., Scott, E. J. \& Pollard, J. (2010). The role of competition in word learning via referent selection. Developmental Science r3, 706-13.

Huttenlocher, J., Haight, W., Bryk, A., Seltzer, M. \& Lyons, T. (I99I). Early vocabulary growth: relation to language input and gender. Developmental Psychology 27(2), 236-48.

Kagan, J., Reznick, J. S. \& Snidman, N. (1987). The physiology and psychology of behavioral inhibition in children. Child Development 58(6), I 459-73.

Kelly, D. J. (I998). A clinical synthesis of the 'late talker' literature: implications for service

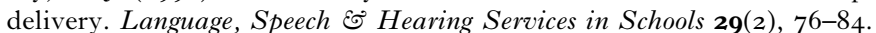

Kucker, S. C., McMurray, B. \& Samuelson, L. K. (2015), Slowing down fast mapping: redefining the dynamics of word learning. Child Development Perspectives 9, 74-8.

Kucker, S. C., and Samuelson, L. K. (2012). The first slow step: differential effects of object and word-form familiarization on retention of fast-mapped words. Infancy 17, 295-323.

Landau, B., Smith, L. B. \& Jones, S. S. (I988). The importance of shape in early lexical learning. Cognitive Development 3(3), 299-32 I.

Levin, I. P. \& Hart, S. S. (2003). Risk preferences in young children: early evidence of individual differences in reaction to potential gains and losses. Fournal of Behavioral Decision Making 5, 397-4I3.

Mareschal, D., Johnson, M. H., Sirois, S., Spratling, M., Thomas, M. S. C. \& Westermann, G. (2007). Neuroconstructivism-I: how the brain constructs cognition. Oxford: Oxford University Press.

Markman, E. M. \& Hutchinson, J. E. (I984). Children's sensitivity to constraints on word meaning: taxonomic versus thematic relations. Cognitive Psychology r6(I), I-27.

Markman, E. M. \& Wachtel, G. W. (I 988). Children's use of mutual exclusivity to constrain the meanings of words. Cognitive Psychology 20, I 2 I-57.

Markman, E. M., Wasow, J. L. \& Hansen, M. B. (2003). Use of the mutual exclusivity assumption by young word learners. Cognitive Psychology 47, 24I-75.

Markson, L. \& Bloom, P. (r 997). Evidence against a dedicated system for word learning in children. Nature 385(66 I 9$)$, 8 I $3-5 .^{-}$

McMurray, B., Horst, J. S. \& Samuelson, L. K. (2012). Word learning emerges from the interaction of online referent selection and slow associative learning. Psychological Review II9(4), 83 I-77.

Mervis, C. B. \& Bertrand, J. (I 994). Acquisition of the Novel Name-Nameless Category $\left(\mathrm{N}_{3} \mathrm{C}\right)$ principle. Child Development 65, $\mathbf{1} 646-62$.

Munro, N., Baker, E., McGregor, K., Docking, K. \& Arciuli, J. (2012). Why word leaning is not fast. Frontiers in Psychology 3, I-Io.

Perry, L. K. (2015) To have and to hold: looking vs. touching in the study of categorization. Frontiers in Psychology. 6, I 78. Online: <https://doi.org/10.3389/fpsyg.201 5.00 I $78>$.

Putnam, S. P., Gartstein, M. A. \& Rothbart, M. K. (2006). Measurement of fine-grained aspects of toddler temperament: the Early Childhood Behavior Questionnaire. Infant Behavior and Development 29(3), 386-40 I.

Quine, W. V. O. ( 1960$)$. Word and object. Cambridge, MA: MIT Press.

Reynolds, K. P. \& Evans, M. A. (2009). Narrative performance and parental scaffolding of shy and nonshy children. Applied Psycholinguistics 30, $36_{3}-84$.

Rudasill, K. M., Prokasky, A., Tu, X., Frohn, S., Sirota, K. \& Molfese, V. J. (20I4). Parent vs teacher ratings of children's shyness as predictors of language and attention skills. Learning and Individual Differences 34, 57-62.

Samuelson, L. K. \& Horst, J. S. (2007). Dynamic noun generalization: moment-to-moment interactions shape children's naming biases. Infancy II(I), 97-I I O. 


\section{HILTON AND WESTERMANN}

Samuelson, L. K., Kucker, S. C. \& Spencer, J. P. (20I6). Moving word learning to a novel space: a dynamic systems view of referent selection and retention. Cognitive Science. Online: <https://doi.org/Io. I I I /cogs. I 2369>.

Samuelson, L. K. \& Smith, L. B. ( I 998). Memory and attention make smart word learning: an alternative account of Akhtar, Carpenter, and Tomasello. Child Development 69, 94-1 04.

Slomkowski, C. L., Nelson, K., Dunn, J. \& Plomin, R. (r 992). Temperament and language: relations from toddlerhood to middle childhood. Developmental Psychology 28(6), Io90-5.

Smith Watts, A. K., Patel, D., Corley, R. P., Friedman, N. P., Hewitt, J. K., Robinson, J. L. \& Rhee, S. H. (20I4). Testing alternative hypotheses regarding the association between behavioral inhibition and language development in toddlerhood. Child Development $\mathbf{8 5}$, I $569-85$.

Spere, K. A., Schmidt, L. A., Theall-Honey, L. A. \& Martin-Chang, S. (2004). Expressive and receptive language skills of temperamentally shy preschoolers. Infant and Child Development I2, I-I I.

Spiegel, C. \& Halberda, J. (20I I). Rapid fast-mapping abilities in 2-year-olds. Fournal of Experimental Child Psychology 109, I32-40.

Twomey, K. E., Ranson, S. L. \& Horst, J. S. (20I4). That's more like it: multiple exemplars facilitate word learning. Infant and Child Development 23, I05-22.

Vlach, H. A. \& Sandhofer, C. M. (2012). Fast mapping across time: memory processes support children's retention of learned words. Frontiers in Psychology 3, 46. Online: $<$ http://doi.org/I0.3389/fpsyg.201 2.00046>.

Whitehurst, G. J. \& Fischel, J. E. (I 994). Practitioner Review: Early Developmental Language Delay: What. If anything. Should the clinician do about it? Fournal of Child Psychology and Psychiatry 35(4), 6 $13-48$.

Wilkinson, K. M., Ross, E. \& Diamond, A. (2003). Fast mapping of multiple words: insight into when 'the information provided' does and does not equal 'the information perceived'. Fournal of Applied Developmental Psychology 24, 739-62.

$\mathrm{Xu}, \mathrm{F}$., Cote, M. \& Baker, A. (2005). Labeling guides object individuation in I2-month-old infants. Psychological Science r6, 372-7.

Zosh, J. M., Brinster, M. \& Halberda, J. (2013). Optimal contrast: competition between two referents improves word learning. Applied Developmental Science 17, 20-8. 